\title{
Isolation and Characterization of Lipoprotein Profiles in Newborns by Density Gradient Ultracentrifugation
}

\author{
M. ROSSENEU, ${ }^{(21)}$ J. P. VAN BIERVLIET, J. BURY, AND N. VINAIMONT \\ Department of Clinical Biochemistry [M.R., J.B., N.V.] and Department of Pediatrics [J.P.V.B.] A.Z. St.-Jan \\ Ruddershovelaan 10, B-8000 Brugge, Belgium
}

\begin{abstract}
Summary
Lipoproteins in newborn plasma were isolated from a minimal sample amount $(0.3 \mathrm{ml})$ by a single-step ultracentrifugation in a density gradient, spanning the density range $1.02-1.20 \mathrm{~g} / \mathrm{ml}$. After $66 \mathrm{~h}$ ultracentrifugation in a swinging-bucket rotor, the content of the tube was eluted and collected in $0.4 \mathrm{ml}$ fractions. Cholesterol and apoproteins AI, AII, and B were assayed in each fraction yielding both the distribution and composition of the very low density lipoprotein (VLDL), low density lipoprotein (LDL), high density lipoprotein $\left(\mathrm{HDL}_{2}\right.$, and $\left.\mathrm{HDL}_{3}\right)$. Newborn plasma was characterized by a low amount of triglyceride-poor and cholesterol ester-rich VLDL and high content of $\mathrm{HDL}_{2}$ and $\mathrm{HDL}_{3}$. The VLDL and LDL concentrations increased drastically between 0 and 7 days together with the triglyceride content of the VLDL.

At 30 days the lipid composition of VLDL was similar to that of adults, whereas the lipid/protein content remained low both in VLDL and LDL. The composition of $\mathrm{HDL}_{2}$ and $\mathrm{HDL}_{3}$ remained constant during this period, the percentage of $\mathrm{HDL}_{2}$ being higher in newborns than in adults. These compositional changes were reflected in the microviscosity of the lipoproteins, specially in the VLDL fraction.
\end{abstract}

Abbreviations

d, density

HDL, high density lipoproteins,

IDL, intermediate density lipoproteins

LDL, low density lipoproteins,

VLDL, very low density lipoproteins,

VLDL-C, LDL-C, HDL-C, VLDL, LDL, HDL cholesterol

The investigation of plasma lipoprotein profiles in newborns is mostly limited by the available volume of the samples. Conventional isolation techniques, by sequential ultracentrifugation, for VLDL, LDL, HDL and their subfractions require $5 \mathrm{ml}$ plasma whereas only $1-2 \mathrm{ml}$ blood can easily be drawn by venapuncture in newborns. Recently, Nillson et al. (10) have adapted the singlespin ultracentrifugation procedure, previously described by Foreman et al. (5), to the analysis of 200-1000 $\mu \mathrm{l}$ plasma. We have applied this procedure to the quantitation of the lipoprotein profiles in newborns at 0,7 and 30 days in order to obtain the compositional analysis of the various lipoprotein fractions. As previously shown $(17,18)$ the lipoprotein patterns in newborns are profoundly modified during the first month of life when several synthetic and catabolic pathways are developing.

The single-spin ultracentrifugation procedure enables further investigation of these metabolic events and of their impact on the plasma lipoprotein distribution and composition.

\section{MATERIALS AND METHODS}

Newborn sera. Blood samples were obtained from male $(n=5)$ and female $(n=5)$ infants at 0,7 and 30 days. Only full-term born infants were selected and neonates with history of chronic maternal-foetal problems such as diabetes or hypertension were not included in the study. All infants were born after uneventful delivery. All subjects were investigated after informed consent had been obtained from their parents. A blood sample was obtained, immediately after delivery and clamping of the umbilical cord, from the umbilical vein. Blood samples at 7 and 30 days were drawn by venapuncture after $7 \mathrm{~h}$ fasting. Blood was allowed to clot at room temperature for about $30 \mathrm{~min}$ and the serum separated at $4^{\circ} \mathrm{C}$ at $10,000 \mathrm{rpm}$. Serum samples were stored at $4^{\circ} \mathrm{C}$ in the presence of $0.05 \%$ EDTA pH 7 for maximum 5 days.

Density gradient ultracentrifugation. The single-spin density ultracentrifugation was based on the method proposed by Nillson $e t$ al. (10), using a slightly modified gradient for a better separation of the HDL subclasses.

As neonates have low serum lipid and lipoprotein values (3), $0.5 \mathrm{ml}$ serum was used for the 0 and 7 days samples while $0.3 \mathrm{ml}$ samples were spun at 30 days.

The ultracentrifugal runs were carried out in an International IEC B.60 ultracentrifuge, using a SB 283 swinging-bucket rotor, in cellulose nitrate tubes with a capacity of $12.5 \mathrm{ml}$.

The gradients were prepared as follows: $500 \mathrm{mg}$ sucrose was weighed on the bottom of the tube; on top of this salt solutions were layered in the following sequence: $5 \mathrm{ml}$ of $4 \mathrm{M} \mathrm{NaCl}, 0.5 \mathrm{ml}$ serum, and $6.4 \mathrm{ml}$ of a $0.67 \mathrm{M} \mathrm{NaCl}$ solution containing $0.05 \%$ EDTA. Each discontinuous gradient was centrifuged at $10^{\circ} \mathrm{C}$ for $66 \mathrm{~h}$ at 39,000 rpm. After the run, the gradient was eluted from the top layer by means of a Buchler Auto-Densi-flow II (Buchler Instruments Searle Analytic Inc. Fort-Lee NJ) coupled to a peristaltic pump operating at a flow rate of $0.5 \mathrm{ml} / \mathrm{min}$. The effluent was monitored at $280 \mathrm{~nm}$ with a Pye-Unicam spectrophotometer equipped with a $8 \mu \mathrm{l}$ flow-through cell and $0.45 \mathrm{ml}$ fractions were collected.

Identical gradients were constructed for determining the density profile in which $0.5 \mathrm{ml}$ of a $4 \mathrm{M} \mathrm{NaCl}$ solution $(\mathrm{d}=1.15 \mathrm{~g} / \mathrm{ml})$ containing $5 \%$ albumin was used instead of a serum sample. The density of the salt gradient was measured by refractometry, after calibration by picnometry.

Chemical analysis of the lipoprotein fractions. In order to obtain the complete apoprotein and lipid profiles in the newborn sera, the apoproteins AI and AII were assayed in the HDL fraction and apoprotein B was assayed in the VLDL and LDL peaks. These analyses were performed by immunonephelometry (14-16) and necessitated only $50 \mu \mathrm{l}$ of each fraction. The inter and intraassay coefficients of variations for the apoprotein assays amount to respectively, 6 and 7\%, for all apoproteins (14-16). Cholesterol was assayed using a fluorimetric technique described for the cholesterol quantitation in cultured cells (6), which was adapted to lipoprotein cholesterol assay. The precision of this technique amounts to $4 \%$.

The lipid composition of each lipoprotein class was quantitated after combining the fractions from each lipoprotein peak. Free and esterified cholesterol, triglycerides, fatty acids, and phospho- 
lipids were assayed by thin layer chromatography with flameionization detection on the Iatroscan TH 10 (Iatron Lab.) using 1octadecanol as an internal standard (19). Before extraction with chloroform-methanol $(2 / 1, v / v)$, the fractions were washed with $0.2 \% \mathrm{CaCl}_{2}$. Total and $\mathrm{HDL}$ cholesterol in the serum samples were assayed enzymatically $(9,11)$ and apoproteins AI, AII, and B by immunonephelometry (14-16) to check on the recovery of the fractions.

Measurement of the fluidity of the lipoprotein lipids. The fluidity of the lipids in VLDL, LDL and $\mathrm{HDL}_{2}$ was measured by fluorescence polarization on a Elscint microviscosimeter after labeling with the lipophilic probe diphenyl hexatriene (12). The polarization ratio was measured as a function of temperature between 15$45^{\circ} \mathrm{C}$ to detect any phase transition in the lipid phase. Measurements were also carried out on a triglyceride dispersion (triolein), on an aqueous dispersion of cholesterol oleate and cholesterol oleate-triglycerides mixtures prepared by sonication of $400 \mu \mathrm{g}$ lipid in $3 \mathrm{ml}$ Tris- $\mathrm{HCl}$ buffer $0.01 \mathrm{M}$, pH 8.1 for $30 \mathrm{~min}$ using a Branson sonifier (13).

\section{RESULTS}

Lipoprotein profiles in newborns. The absorbance profile and the density gradient corresponding to the ultracentrifugal run of a cord-blood sample are shown on Figure 1. The first peak detected between tubes 1 and 3 corresponds to the VLDL fraction with a density less than $1.030 \mathrm{~g} / \mathrm{ml}$. The LDL region between tubes 4 and 10 has a maximum at a density of $1.044 \mathrm{~g} / \mathrm{ml}$. The HDL region could be separated in $\mathrm{HDL}_{2 \mathrm{a}}$ and $\mathrm{HDL}_{2 b}$, according the classification of Blanche et al. (2) with densities of 1.076 and 1.092 $\mathrm{g} / \mathrm{ml}$ and $\mathrm{HDL}_{3 \mathrm{a}}$ and $\mathrm{HDL}_{3 \mathrm{~b}}$ with respective densities of 1.120 and $1.142 \mathrm{~g} / \mathrm{ml}$. A VHDL fraction contaminated with albumin was collected at a density of $1.165 \mathrm{~g} / \mathrm{ml}$. The corresponding protein and cholesterol profiles in newborns at 0,7 and 30 days are depicted in Figures 2-4. Three representative patterns in breast-fed infants were selected: infant 1 (Fig. 2) had low VLDL, low LDL and high HDL at birth. VLDL and LDL increased at 7 days, and VLDL subsequently decreased at 30 days whereas LDL and HDL concentrations remained constant. Infant 2 (Fig. 3) had elevated VLDL concentration at birth, which normalized between 0 and 30 days. Infant 3 (Fig. 4) had an elevated LDL concentration from birth until 30 days.

The heterogeneity of the lipoprotein profiles in the infants is very pronounced. The percentages of VLDL, $\mathrm{LDL}, \mathrm{HDL}_{2}$ and $\mathrm{HDL}_{3}$ vary not only with age but also very strongly among neonates born under normal conditions. The distribution of the $\mathrm{HDL}$ subclasses, $\mathrm{HDL}_{2}$ and $\mathrm{HDL}_{3}$ is also very heterogeneous.

Lipoprotein concentrations in newborn plasma. Table 1 summa- rizes the concentrations of the various lipoproteins in newborn plasma, expressed as cholesterol content in VLDL, LDL, $\mathrm{HDL}_{2}$ and $\mathrm{HDL}_{3}$, together with the concentration of apo AI, AII, and B. The mean values calculated on 10 newborns indicate that the major cholesterol increase between 0 and 7 days occurs within VLDL and LDL fractions. This process is accompanied by a concommitant increase of apo B in agreement with previous results (17). Between 7 and 30 days, VLDL decrease to a value close to their concentration at birth whereas LDL remain constant and apo B decreases only slightly. Apo AI and apo AII increase mostly between 7 and 30 days (5). HDL cholesterol does not vary significantly between 0 and 7 days, but increases between 7 and 30 days both in the $\mathrm{HDL}_{2}$ and the $\mathrm{HDL}_{3}$ fractions. The percentual distribution of the VLDL, LDL, $\mathrm{HDL}_{2}$ and $\mathrm{HDL}_{3}$ cholesterol in newborns at 0,7 and 30 days was calculated from the plasma concentrations. The highest percentages of VLDL-C and LDL-C are present at 7 days whereas at 30 days the VLDL percentage is close to that at birth, with an elevated percentage of LDL and a decreased percentage of HDL. At birth HDL consists for $49 \%$ of $\mathrm{HDL}_{2}$ and this high percentage persists at 7 and 30 days with respectively 46.5 and $48 \% \mathrm{HDL}_{2}$.

The proportion of lipid and protein in the various lipoprotein fractions does not vary significantly between 0 and 30 days. The cholesterol/protein ratio in HDL amounts to 0.4 and is similar to the value measured in adults, using the same technique. The cholesterol/apo B ratio is significantly lower both in VLDL and LDL amounting to respectively 1.2 compared to 1.4 and 0.9 compared to 1.1 .

The lipid distribution in the various lipoproteins, summarized in Table 2, shows that the lipid composition of LDL and HDL remains constant between 0 and 30 days. These values are well comparable to those measured in adults.

As shown on Fig. 5 the lipid fluidity in $\mathrm{LDL}$ and $\mathrm{HDL}_{2}$ varies little with the age of the infants and is close to that of adults.

In VLDL, however, the cholesterol ester/triglyceride ratio strongly varies between birth and 30 days. Cord-blood VLDL contains as much cholesterol esters as triglycerides whereas the triglyceride/cholesterol ester ratio increases at 7 and 30 days to a value close to that of adults (12). These compositional variations are clearly reflected in the variations of the fluidity of the VLDL lipids. The fluorescence polarization ratio, which is inversely proportional to the lipid fluidity, is higher at birth than at 7 and 30 days.

This parameter is strongly dependent on the triglycerides to cholesterol ester content of the particles (12). This is further illustrated in Fig. 6, where $P$ is plotted as a function of the cholesterol esters/triglyceride ratio for both infant VLDL and

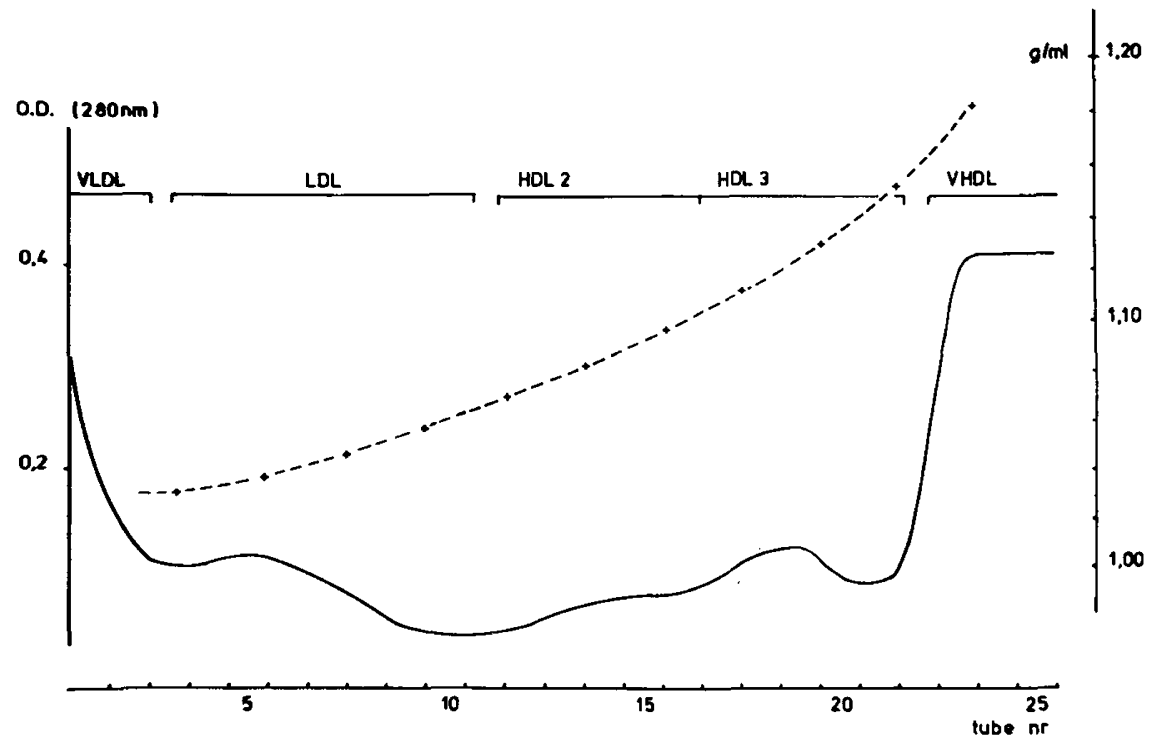

Fig. 1. Absorbance profile obtained after isopycnic ultracentrifugation of $0.3 \mathrm{ml}$ serum of a 7-day-old infant. The optical density of the eluate was continuously measured at $280 \mathrm{~nm}$ and $0.5 \mathrm{ml}$ fractions were collected. The density profile was measured by picnometry. 

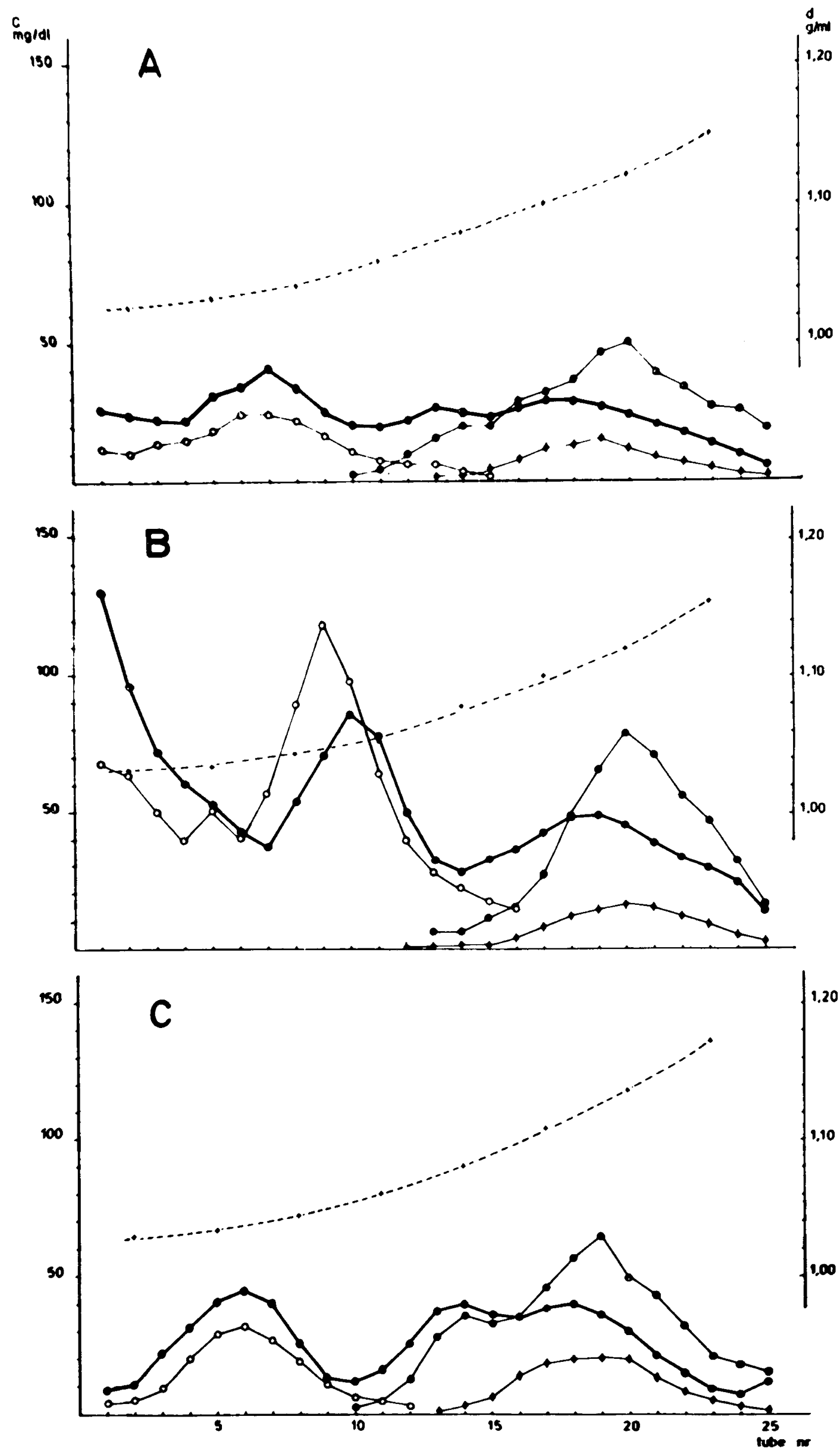

Fig. 2. Lipid and apoprotein profiles of the lipoprotein fractions of the serum of infant 1 at $(A) 0 ;(B) 7 ;(C) 30$ days, obtained by single-spin ultracentrifugation $(-O)$ : cholesterol: $\left({ }^{-}\right)$): apo B; $(\odot-\odot)$ : apo AI; $(\circlearrowleft-\phi)$ : apo AII. 

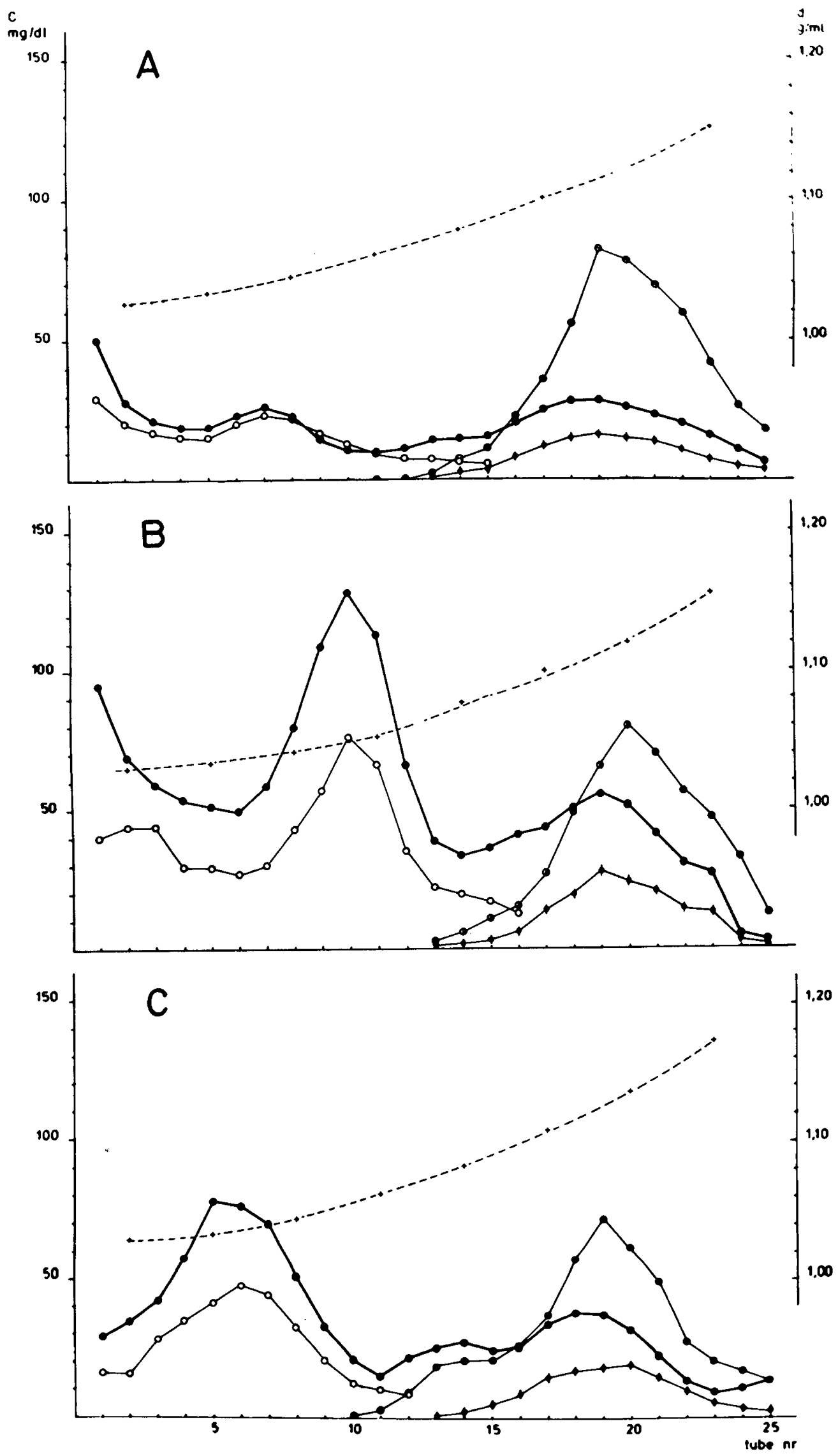

Fig. 3. Infant 2, see legend for Figure 2.

cholesterol oleate-triolein dispersions. The $P$ values of VLDL are higher than in the pure lipid dispersions due to the contribution of phospholipids and apoproteins (13), but show a similar dependence on the lipid composition, both in infants and adults. $m$

$\$ 10$

1.20

20

10
DISCUSSION

In previous studies we followed the evolution of the plasma apo AI, AII, and B proteins during the first month of life together with 

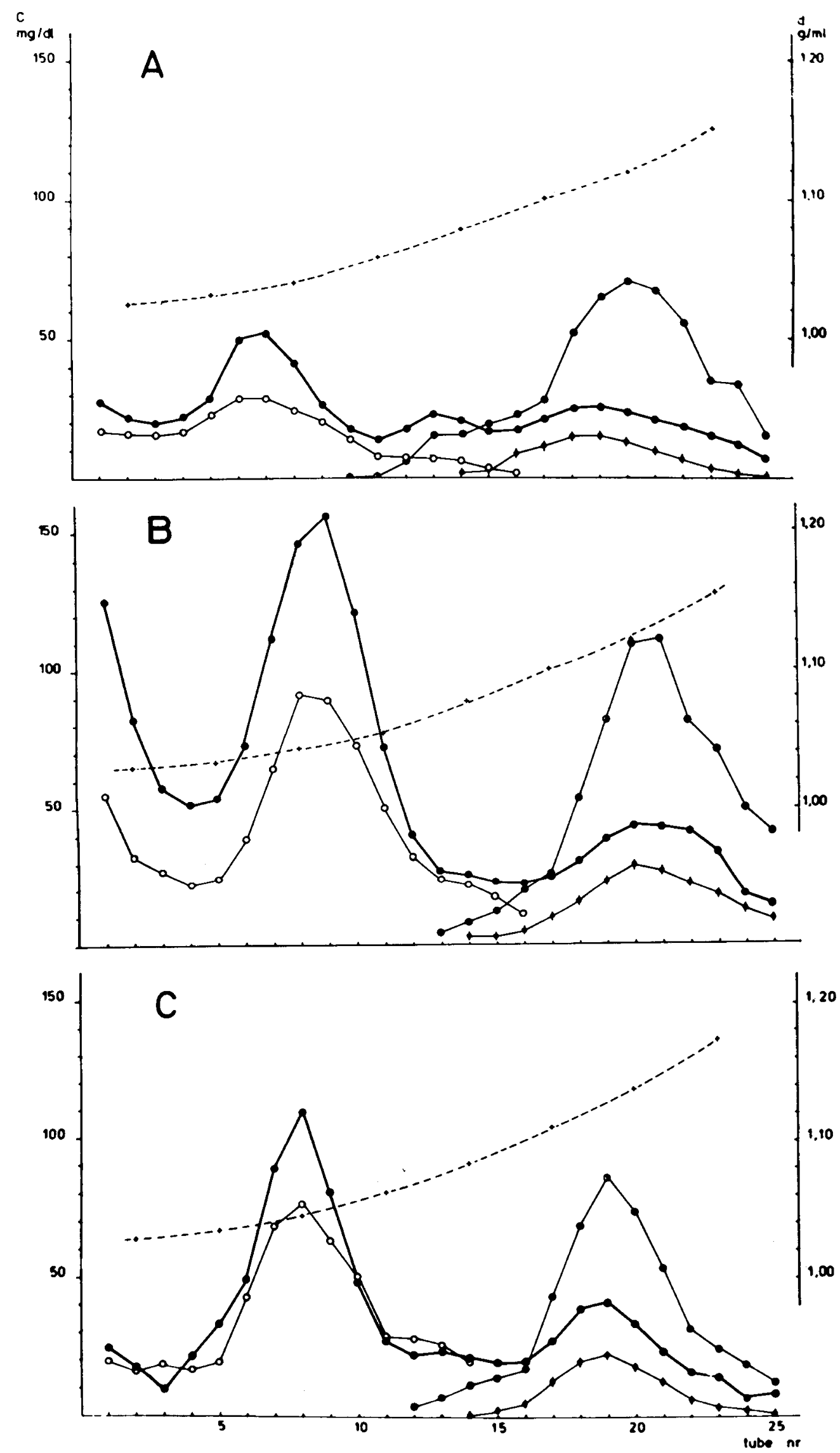

Fig. 4. Infant 3, see legend for Figure 2.

the HDL and LDL + VLDL cholesterol $(17,18)$. The influence of the fatty acid content of the diet could also be evaluated (5).

The present results focus on the distribution and composition of the various lipoprotein fractions in newborns during the first month of life. Using isopycnic ultracentrifugation we could isolate and quantitate the VLDL, LDL, $\mathrm{HDL}_{2}$, and $\mathrm{HDL}_{3}$ fractions separately and analyze their respective protein and lipid composition. These results indicate that the metabolism of VLDL and 
Table 1. Lipoprotein concentrations in newborn plasma. Lipoprotein concentrations in newborn plasma. Results are expressed as mean values \pm standard deviation from data obtained on 10 breast-fed infants ${ }^{1}$

\begin{tabular}{|c|c|c|c|c|c|c|c|c|}
\hline Days & $\begin{array}{c}\text { TC } \\
(\mathrm{mg} / \mathrm{dl})\end{array}$ & $\begin{array}{l}\text { VLDL-C } \\
\text { (mg/dl) }\end{array}$ & $\begin{array}{l}\text { LDL-C } \\
(\mathrm{mg} / \mathrm{dl})\end{array}$ & $\begin{array}{l}\mathrm{HDL}_{2}-\mathrm{C} \\
(\mathrm{mg} / \mathrm{dl})\end{array}$ & $\begin{array}{l}\mathrm{HDL}_{3}-\mathrm{C} \\
(\mathrm{mg} / \mathrm{dl})\end{array}$ & $\begin{array}{c}\text { apo B } \\
(\mathrm{mg} / \mathrm{dl})\end{array}$ & $\begin{array}{l}\text { apo AI } \\
(\mathrm{mg} / \mathrm{dl})\end{array}$ & $\begin{array}{l}\text { apo AII } \\
(\mathrm{mg} / \mathrm{dl})\end{array}$ \\
\hline 0 & $68.8 \pm 7.6$ & $8.7 \pm 3.1$ & $26.9 \pm 5.9$ & $16.9 \pm 2.2$ & $17.6 \pm 1.5$ & $48.5 \pm 5.0$ & $71.9 \pm 6.5$ & $15.7 \pm 2.0$ \\
\hline 7 & $121.2 \pm 15.2$ & $23.9 \pm 5.6$ & $64.3 \pm 17.6$ & $16.2 \pm 4.2$ & $18.2 \pm 4.2$ & $97.5 \pm 12.0$ & $77.6 \pm 12.2$ & $17.7 \pm 2.6$ \\
\hline
\end{tabular}

${ }^{1}$ For definitions see "Abbreviations."

Table 2. Lipid distribution of the lipoproteins in newborn plasma $(w t \%)$. Lipid distribution (wt \%) of the lipoproteins in plasma of breast-fed infants as a function of age. Mean values from duplicate measurements

\begin{tabular}{rlrrrr}
\hline Lipoprotein & Lipid $^{1}$ & 0 day & 7 day & 30 day & Adult \\
\hline \multirow{5}{*}{ VLDL } & CE & 23.5 & 13.8 & 14.2 & 13.5 \\
& FC & 7.8 & 8.4 & 7.7 & 5.1 \\
& TG & 20.5 & 47.1 & 47.7 & 52.2 \\
& PL & 44.0 & 28.0 & 26.2 & 29.6 \\
& FFA & 3.2 & 2.7 & 1.4 & 1.7 \\
& & & & & \\
LDL & CE & 37.6 & 34.8 & 37.2 & 49.5 \\
& FC & 7.9 & 12.0 & 10.9 & 11.9 \\
& TG & 15.0 & 14.3 & 17.3 & 16.5 \\
& PL & 32.0 & 35.0 & 32.6 & 22.3 \\
& FFA & 5.1 & 3.8 & 2.0 & 1.2 \\
& & & & & \\
& CE & 27.6 & 27.8 & 27.4 & 37.9 \\
HDL $_{2}$ & FC & 6.9 & 8.5 & 5.6 & 10.2 \\
& TG & 8.9 & 10.0 & 7.2 & 3.1 \\
& PL & 45.8 & 48.1 & 53.0 & 37.9 \\
& FFA & 4.8 & 3.7 & 3.6 & 1.9 \\
& & & & & \\
& CE & 29.3 & 29.5 & 29.5 & 37.2 \\
& FC & 4.6 & 5.4 & 6.0 & 5.5 \\
HDL $_{3}$ & TG & 7.2 & 3.1 & 6.8 & 5.1 \\
& PL & 53.9 & 54.2 & 52.5 & 52.4 \\
& FFA & 5.0 & 4.1 & 3.7 & 1.6 \\
\hline
\end{tabular}

${ }^{1}$ Definitions: CE, cholesterol esters; FC, free cholesterol; TG, triglycerides; PL, phospholipids; and FFA, free fatty acids.

LDL does not match completely between 0 and 7 days, as we observe a proportionally higher increase of VLDL than LDL during this period. The VLDL accumulation, that does disappear at 30 days might be due to a defective activity of the lipoprotein lipase, mediating the interconversion of VLDL to LDL.

Except in infants born under perinatal stress, VLDL are mostly low at birth and a drastic increase of both VLDL and LDL is observed between 0 and 7 days. During this period the HDL concentration as well as the $\mathrm{HDL}_{2} / \mathrm{HDL}_{3}$ ratio remain constant. The percentage of $\mathrm{HDL}_{2}$ in newborns is significantly higher than in adults, especially in men (8). Significant compositional changes occur in the lipoproteins present in the $\mathrm{d}<1.025 \mathrm{~g} / \mathrm{ml}$ peak, within the 7 first days of life. At birth the particles are rich in cholesterol esters and relatively poor in triglycerides whereas the triglyceride content at 7 days exceeds that of the particles at 30 days.

In a recent paper Davis and Forte (4) reported the isolation and characterization of intermediate density and low density lipoproteins, showing an enrichment of the IDL fraction in total cholesterol and phospholipids. In our study the lipoprotein separation by isopycnic ultracentrifugation did not enable the differentiation between VLDL and IDL present in the $d<1.025 \mathrm{~g} / \mathrm{ml}$ peak whereas $\mathrm{HDL}_{2}$ and $\mathrm{HDL}_{3}$ could be resolved. The compositional changes observed in the VLDL peak might therefore be interpreted in terms of a modification of the relative proportion of VLDL and IDL between birth and 30 days. At birth the $d<1.025$ $\mathrm{g} / \mathrm{ml}$ peak would consist mostly of cholesterol esters-rich IDL, in agreement with the observations of Davis and Forte (4). As the

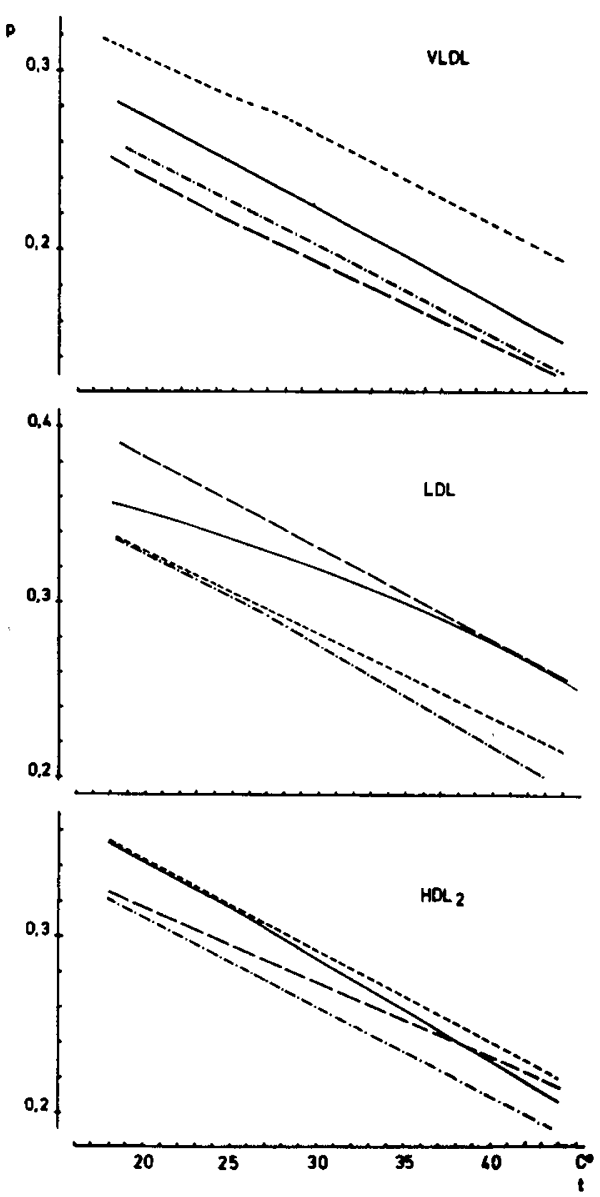

Fig. 5. Fluorescence polarization ratio $p$ of the lipoprotein fractions (VLDL, LDL, and $\mathrm{HDL}_{2}$ ) of an infant at (- -): 0 day; (- - ): 7 days; $(\longrightarrow . \longrightarrow)$ : 30 days compared to adult $(\longrightarrow)$ values.

VLDL concentration increases between 0 and 7 days, this peak becomes relatively enriched in VLDL. At 30 days VLDL still predominates compared to IDL, though the total concentration of the VLDL + IDL lipids has returned to its level at birth.

The composition of newborn VLDL and LDL indicate that these particles are enriched in apo B compared to the lipoproteins isolated from adult plasma (1). In infancy most of the cholesterol carried by the lipoproteins is rapidly incorporated into the growing tissues, so that the lipid/apo B ratio is low. At maturity the lipid load of the VLDL and LDL increases as this exchange process slows down. This observation is most striking in the VLDL and LDL classes whereas the lipid/protein composition of infant HDL does not significantly differ from that reported in the adult.

Results of previous studies on the lipoprotein composition in newborn plasma yielded contradictory results $(7,20)$. Carlsson et al. (3) reported that only $30 \%$ of the cord blood triglycerides is present in VLDL, in agreement with our data on the low levels of triglyceride-poor VLDL in newborns at 0 day. According to Winkler et al. (20) $40 \%$ of the phospholipids sedimented in a d > 1.21 fraction, which was not observed in our study. These authors though agreed on the low triglyceride content of the VLDL fraction. As these analyses must be performed on microquantities 


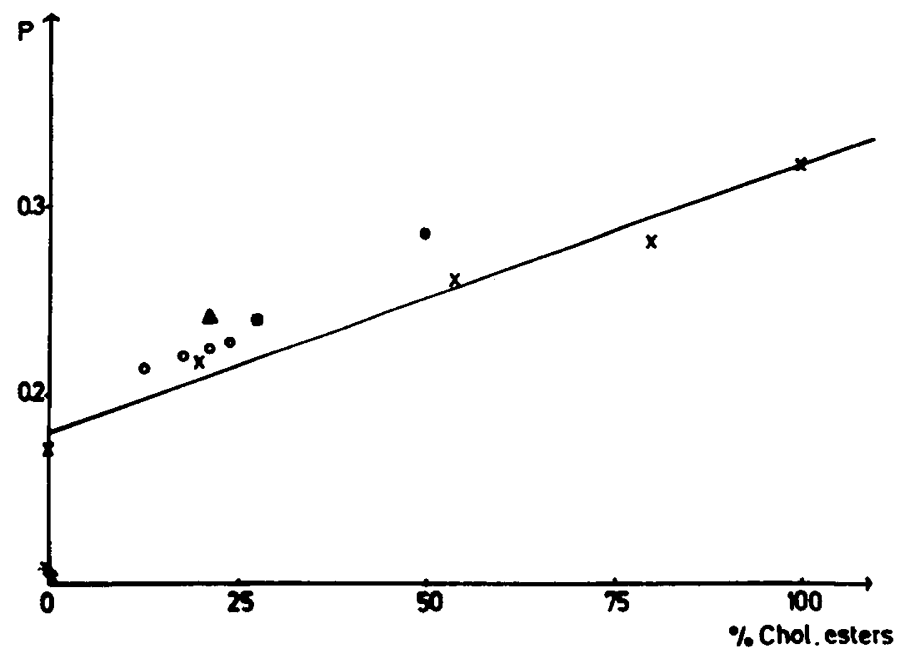

Fig. 6. Dependence of the fluorescence polarization ratio $p$ at $25^{\circ} \mathrm{C}$ upon the \% of cholesterol esters in: $(\mathrm{X})$ : cholesterol oleate-triolein dispersions, infant VLDL at $(\bullet): 0 ;(\Delta): 7$; and $(\square): 30$ days and in adult VLDL $(O)$. The \% of cholesterol esters is expressed as:

\section{Weight cholesterol esters}

Weight cholesterol esters + weight triglycerides

of samples, technical problems can lead to erroneous results and the techniques should be carefully standardized. The single-spin ultracentrifugation is especially suited for this kind of study, given its resolution and reproducibility. The study of the influence of dietary parameters on the lipoprotein composition and distribution in newborn plasma, using the same techniques, is currently under progress.

\section{REFERENCES AND NOTES}

1. Albers, J., Cabana, V., and Hazzard, W.: Immunoassay of human plasma apolipoprotein B. Metabolism., 24: 1339 (1975).

2. Blanche, P., Gong, E., Forte, T., and Nichols, A.: Characterization of human high-density lipoproteins by gradient gel electrophoresis. Biochim. Biophys. Acta, 665: 408 (1981).

3. Carlson, L. A. and Hardell, L. I.: Very-low density lipoproteins in cord blood Clin. Chim. Acta, 90: 295 (1978).
4. Davis, P. A. and Forte, T. M.: Neonatal umbilical cord blood lipoproteins Isolation and characterization of intermediate density and low density lipoproteins. Arteriosclerosis, 2: 37 (1982).

5. Foreman, J., Karlin, J., Edelstein, C., Juhn, D., Rubenstein, A., and Scanu, A. Fractionation of human serum lipoproteins by single-spin gradient ultracentrifugation: quantification of apolipoproteins $\mathrm{B}$ and $\mathrm{AI}$ and lipid components. J. Lipid Res., 18: 759 (1977).

6. Gamble W., Vaughan M., Kruth H. S., and Avignan J.: Procedure for determination of free and total cholesterol in micro or nanogram amounts suitable for studies with cultured cells. J. Lipid Res., 19: 1068 (1978).

7. Hardell, L. I. and Carlson, L. A.: Concentration and composition of human serum lipoproteins at birth. Clin. Chim. Acta, 90: 285 (1978).

8. Kirstein, P. and Carlson, K.: Determination of the cholesterol content of highdensity lipoprotein subfractions $\mathrm{HDL}_{2}$ and $\mathrm{HDL}_{3}$, without contamination of Lp (a) in human plasma. Clin. Chem. Acta, 113: 123 (1981).

9. Lopes-Virella, M. F., Stone, P., Ellis, S. and Colwell, J.: Cholesterol determination in high-density lipoproteins separated by three different methods. Clin. Chem., 23: 882 (1977).

10. Nillson, J., Mannickarottu, V., Edelstein, C., and Scanu, A.: An improved detection system applied to the study of serum lipoproteins after single-step density gradient ultracentrifugation. Anal. Biochem., 110: 342 (1981)

11. Röschlau, P., Bernt, E., and Gruber, W.: Enzymatische Bestimmung der GesamtCholesterins im Serum. Z. Klin. Chem. Klin. Biochem., 12: 403 (1974).

12. Rosseneu, M., Soetewey, F., Vercaemst, R., Lievens, M., and Peeters, H.: Microviscosity of plasma lipoproteins and lipids. In: Protides Biol. Fluids, H. Peeters (Ed.) Vol 25 p. 47 (Pergamon Press, Oxford, 1977).

13. Rosseneu, M.: Reassembly of lipids and apoproteins. In: H. Peeters (ed.): The Lipoprotein Molecule. p. 129 (Plenum Press, London, 1978).

14. Rosseneu, M. Vercaemst, R. Vinaimont, N. Van Tornout, P. Henderson, L. and Herbert, P.: Quantitative determination of the human plasma apolipoprotein AI by immunonephelometry. Clin. Chem., 27: 856 (1981).

15. Rosseneu, M., Vinaimont, N., Vercaemst, R., De Keersgieter, W., and Belpaire, F.: Standardization of immunoassays for the quantitation of plasma apo $B$ protein. Anal. Biochem., 116: 204 (1981).

16. Rosseneu, M., Vinaimont, N., Henderson, L., Herbert, P., and Belpaire, F. Quantitation of the human plasma apo AII protein by immunonephelometry. Clin. Chem., (in press)

17. Van Biervliet, J. P., Vercaemst, R., De Keersgieter, W., Vinaimont, N., Caster, H., and Rosseneu, M.: Evolution of lipoprotein patterns in newborns. Acta Paediatr. Scand. 69: 593 (1980)

18. Van Biervliet, J. P., Vinaimont, N., Caster, H., Vercaemst, R., and Rosseneu, M. Plasma apoproteins and lipid patterns in newborns. Influence of nutritional factors. Acta Paediatr. Scand., 70: 851 (1981)

19. Van Tornout, P., Vercaemst, R., De Keersgieter, W., Lievens, M., Caster, H., and Rosseneu, M.: Use of 1-Octadecanol as internal standard for plasma lipids quantitation on chromarods. J. Chromatogr., 164: 222 (1979).

20. Winkler, L., Schlag, B., and Goetze, E.: Concentration and composition of the lipoprotein classes of human umbilical cord serum. Clin. Chim. Acta, 76: 187 (1977).

21. Requests for reprints should be addressed to: Dr. M. Rosseneu, Dept. of Clinical Biochemistry, A. Z. St. Jan Ruddershovelaan 10, B-8000 Brugge, Belgium.

22. Received for publication August 18, 1982.

23. Accepted for publication March 15, 1983. 